\title{
Discrete Devaluations and Multiple Equilibria in a First Generation Model of Currency Crises
}

\author{
Fernando A. Broner, ${ }^{*}$ \\ CREI, Universitat Pompeu Fabra, and CEPR
}

January 2007

\begin{abstract}
The first generation models of currency crises have often been criticized because they predict that, in the absence of very large triggering shocks, currency attacks should be predictable and lead to small devaluations. This paper shows that these features of first generation models are not robust to the inclusion of private information. In particular, this paper analyzes a generalization of the Krugman-Flood-Garber (KFG) model, which relaxes the assumption that all consumers are perfectly informed about the level of fundamentals. In this environment, the KFG equilibrium of zero devaluation is only one of many possible equilibria. In all the other equilibria, the lack of perfect information delays the attack on the currency past the point at which the shadow exchange rate equals the peg, giving rise to unpredictable and discrete devaluations.
\end{abstract}

Keywords: Currency Crises, First Generation Models, Private Information, Discrete Devaluations, Multiple Equilibria.

JEL Classification: D8, E58, F31, F32.

\footnotetext{
${ }^{*}$ Contact: www.crei.cat/people/broner.

${ }^{\dagger}$ I appreciate comments from Roberto Chang, V. V. Chari, Allan Drazen, Jordi Galí, Bernardo Guimarães, Enrique Mendoza, Ivan Pastine, Hélène Rey, Jaume Ventura, an anonymous referee, and seminar participants at CREI-UPF, Harvard, IIES, LSE, MIT, CEPR ESSIM Meeting, NBER EFG Meeting, NBER IFM Meeting, and SED Meeting. I received financial support from the Spanish Ministry of Education and Sciences (ref: SEC2002-03816), the Generalitat de Catalunya (DURSI, SGR2005 0049), and CREA-Barcelona Economics.
} 


\section{Introduction}

Currency crises are characterized by two seemingly contradictory features. On the one hand, currency crises are usually "large," in that they involve massive asset reallocations, wild swings in asset prices, and heavy output losses. On the other hand, currency crises are often triggered by shocks that seem too small to account for these effects. Although these characteristics of crises might suggest some form of irrationality, the literature has provided two types of models that account for some of these features in an environment in which agents are rational. ${ }^{1}$

First generation models of currency crises, starting with Krugman (1979) and Flood and Garber (1984a), view crises as arising from inconsistent policies; in particular, monetization of fiscal deficits together with fixed exchange rates. In these models, the drop in demand for real balances at the time of the crisis leads to a discrete drop in reserves at the Central Bank, even in the absence of a corresponding discrete deterioration in fundamentals. Although these models account for large "attacks," they have the counterfactual implication that these attacks should be predictable and, consequently, lead to no discrete changes in the exchange rate or other asset prices. $^{2}$

Second generation models of currency crises, starting with Obstfeld (1986), account for the unpredictability of crises by assuming the existence of multiple equilibria. ${ }^{3}$ In these models, consumers' expectations can be self-fulfilling because they affect the Central Bank's decision of whether to devalue. One drawback of these models is that they have little to say about the dynamics and timing of crises, as these depend on unmodeled expectational dynamics. Furthermore, Morris and Shin (1998) show that the existence of multiple equilibria in second generation models may not be robust to the inclusion of private information. Morris and Shin present a canonical second generation model and show that, when consumers have private information about the level of fundamentals, the model has a single equilibrium. As a result, in their environment the indeterminacy

\footnotetext{
${ }^{1}$ For a more thorough description of existing models of currency crises and the relationship between first and second generation models, see Jeanne (1999) and Cavallari and Corsetti (2000).

${ }^{2}$ Flood and Garber (1984a) present an extension in which they assume the presence of large unexpected shocks to domestic credit. They show that these large shocks can lead to unexpected crises and discrete devaluations. Drazen and Helpman (1987) and Pastine (2002) present models where a similar mechanism is present. They consider cases in which the Central Bank has incentives to abandon the peg before the attack at a time which is not known to consumers. In equilibrium, this leads to discrete devaluations when the peg is (unexpectedly) abandoned. However, in these papers reserves are continuous and there are no attacks on the currency. Guimarães (2006) presents a model where predictable discrete devaluations are possible in equilibrium. This is because consumers face transaction costs that prevent them from adjusting their portfolio in order to avoid the associated predictable capital losses.

${ }^{3} \mathrm{~A}$ related argument is made by Flood and Garber (1984b) in a study of the consequences of adopting commoditybased money.
} 
on which second generation models depend to account for unpredictable crises and discrete drops in asset prices disappears. ${ }^{4}$

This paper proposes a first generation model of currency crises that accounts not only for the attack on Central Bank reserves, but also for the suddenness, unpredictability, and discrete devaluations associated with currency crises. The only difference between the model proposed in this paper and previous first generation models is that I assume that not all consumers are perfectly informed about the level of fundamentals. In particular, I analyze a generalization of the Krugman-Flood-Garber (KFG) model, in which only a subset of informed consumers knows the level of Central Bank reserves at which the peg will be abandoned, while other, uninformed, consumers have imperfect knowledge about this threshold level of reserves. In this environment, the timing of the crisis is determined by the interplay between the learning process by uninformed consumers in the run up to the crisis, their resulting portfolio reallocation, and their effect on the timing of the attack by informed consumers. As in previous first generation models, when all consumers are informed the attack is predictable and its timing is simply determined by the condition that the shadow exchange rate be equal to the peg. ${ }^{5}$ When some consumers are uninformed, however, the value of the shadow exchange rate is no longer public information and the crisis becomes unpredictable even though its timing is still determined by fundamentals. ${ }^{6}$ When the fraction of informed consumers is sufficiently low, I show that the unpredictability of the crisis increases the range of outcomes that can be sustained in equilibrium. In particular, discrete devaluations can no longer be ruled out, as the associated capital losses are suffered only by uninformed consumers. ${ }^{7,8}$

Figure 1 illustrates the main results of the paper. The top panel presents the set of equilib-

\footnotetext{
${ }^{4}$ Angeletos, Hellwig, and Pavan (2007) show that if past play allows agents to discard the possibility that fundamentals are very weak, then second generation models can have multiple equilibria even in the presence of private information.

${ }^{5}$ The shadow exchange rate is the exchange rate that would prevail at time $t$ if there were an attack on the currency that led to the abandonment of the peg.

${ }^{6}$ Actually, the crisis can be predicted by informed consumers since they know the threshold level of Central Bank reserves. These consumers take advantage of this knowledge and make capital gains. A discrete devaluation is still possible in equilibrium because consumers face short-sale constraints. The crisis is unpredictable from the point of view of both uninformed consumers and the econometrician.

${ }^{7}$ Krugman (1979) includes an extension in which he also introduces uncertainty about the threshold level of Central Bank reserves, by assuming the existence of a finite number of possible threshold levels. Krugman further assumes that all consumers share the same (imperfect) information about this threshold level. He shows that this type of uncertainty can lead to "probing attacks." However, it does not lead to discrete devaluations or multiple equilibria.

${ }^{8}$ Broner (2002) presents a reduced form model of currency crises in which both groups of consumers have private information, and analyzes both the effect of private information on the timing of crises and the role of interest rate policy. Although considerably more involved, the results in Broner (2002) share many characteristics with those in this paper, including the existence of multiple equilibria and discrete devaluations.
} 
rium times at which the crisis can take place, as a function of the fraction of informed consumers $\alpha \in(0,1]$. It is the bifurcation diagram of the game for a particular realization of the threshold level of reserves. The bottom panel depicts the deterioration of fundamentals and the corresponding depreciation of the shadow exchange rate for each crisis time. When the amount of private information is low ( $\alpha$ high), there is a single equilibrium. In this equilibrium, which corresponds to the equilibrium of previous first generation models, the crisis takes place at a time $T_{K F G}$ such that the shadow exchange rate equals the peg and, thus, the size of the devaluation is zero. When the amount of private information is high ( $\alpha$ low) there are multiple equilibria, which differ on informed consumers' propensity to attack the currency. At one extreme, there exists an equilibrium in which the crisis takes place at time $T_{K F G}$ and the size of the devaluation is zero. However, in all other equilibria the crisis takes place later and is associated with discrete devaluations. There exist equilibria such that the crisis can take place at any time between $T_{K F G}$ and some latest time $T_{M A X}$. I present an equilibrium refinement that suggests that the equilibrium likely to be played is one in which the crisis takes place at a time $T_{R E F}>T_{K F G}$. Interestingly, in the refined equilibrium the crisis is delayed as the amount of private information increases (solid line in the top panel).

There are a number of papers, which provide empirical support to the notion that some identifiable groups of agents are better informed and can better predict crises than other market participants. In particular, domestic banks, rich domestic consumers, and large domestic investors seem to be at an informational advantage over foreign investors and the general public. ${ }^{9}$ For example, during the Mexican crisis at the end of 1994, there was uncertainty about both the true level of reserves at the Banco de Mexico (Edwards, 1997) and about the extent to which domestic banks were holding sovereign and stock market risk through swaps (Garber, 1998). As a result, it is likely that domestic banks and other insiders were relatively well informed and could thus predict the timing of the devaluation. In fact, Garber (1998) argues that Mexican banks' purchases of dollars to meet margin calls on their Tesobono and stock swaps may account for the full $\$ 4$ billion drop in Banco de Mexico reserves in the final attack before the peso was floated. Burnside, Eichenbaum, and Rebelo (2001) argue that the Asian currency crises during 1997 were the result of prospective fiscal deficits arising from implicit government guarantees on domestic financial institutions. Given

\footnotetext{
${ }^{9}$ The mechanism proposed in this paper does not depend on which particular group of agents is well informed. In fact, the evidence suggests that the particular group with an informational advantage might be different in different crises.
} 


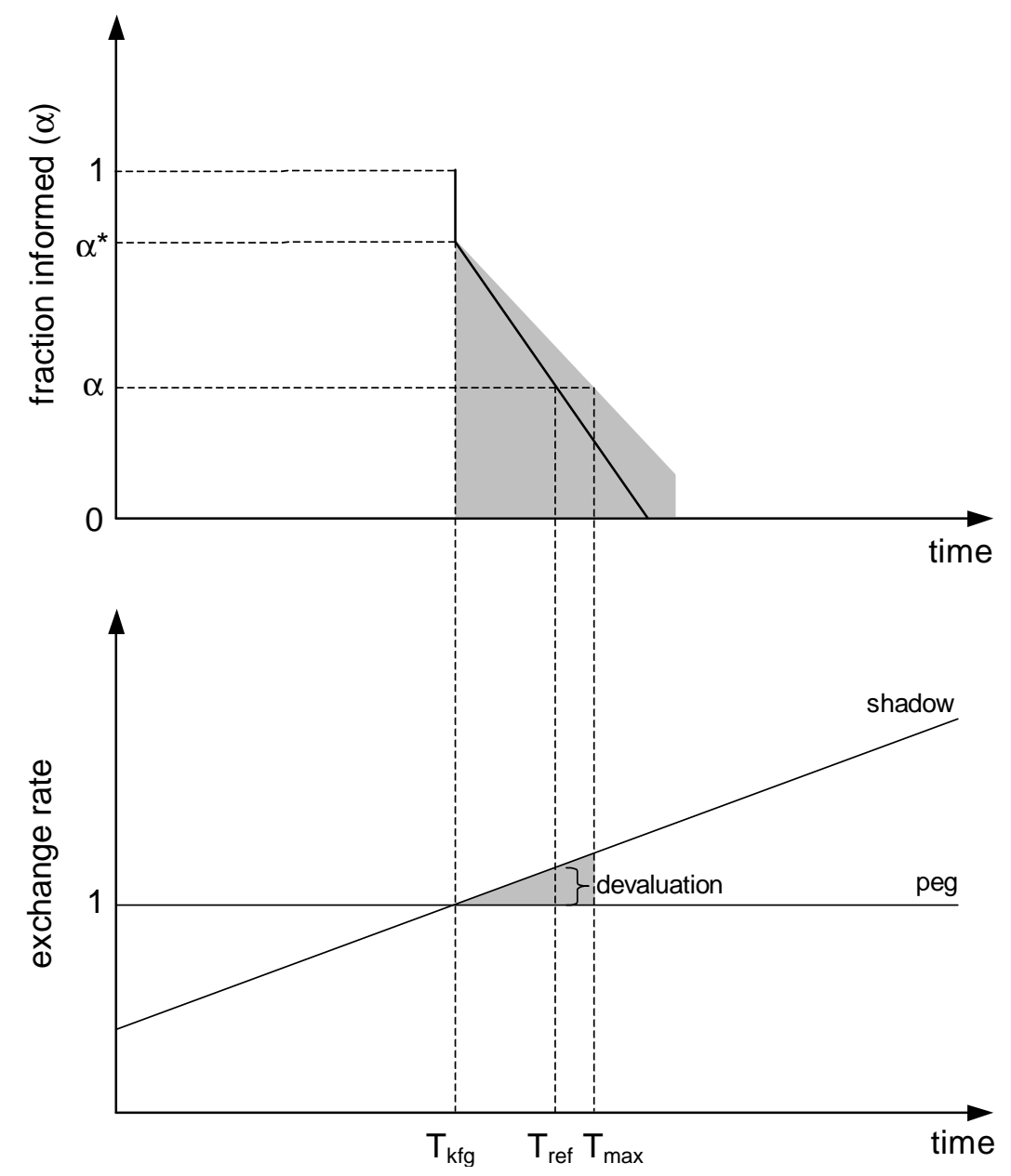

Figure 1: Equilibria and associated devaluations. $\alpha$ denotes the fraction of informed consumers. The solid line in the top panel shows the refined equilibrium.

that the crises caught most observers by surprise, it seems reasonable to suppose that those financial institutions and other insiders had an informational advantage over other investors. During the Russian crisis in 1998 the Central Bank secretely invested a large fraction of the reserves available to back the ruble in Russian short-term debt through offshore firms. Frankel and Schmukler (2000) show that during the crises in Mexico in 1994, and Indonesia, Malaysia, the Philippines, and Thailand in 1997, the discount on closed-end country funds over the price of the underlying assets decreased substantially and even became negative at the time of the crises. Frankel and Schmukler interpret this evidence as suggesting that domestic investors had better information and 
foresaw the crises, while foreign investors reacted with a lag. Halac and Schmukler (2004) show that during the crises in Ecuador in 1999, Argentina in 2001, and Uruguay in 2002, holders of large bank deposits withdrew their funds before the crises to a much greater extent than holders of small deposits, probably reflecting an informational advantage. ${ }^{10}$ Although it is difficult to directly estimate the role of private information during episodes of currency crises, overall there does seem to be substantial indirect evidence consistent with the mechanism proposed in this paper.

Three papers which also explore the role of agents' private information on the timing of currency crises are Morris and Shin (1999), Chari and Kehoe (2003), and Chamley (2003). In a dynamic extension of Morris and Shin (1998), Morris and Shin (1999) argue that crises should take place when fundamentals cross the threshold level that separates the two regions in which the good or bad equilibria are played. Chari and Kehoe (2003) show that when investors have private information, they can infer other investors' private information by observing their actions, which leads to volatile capital flows, unpredictable crises, and herd-like behavior. These two papers differ from this paper in a crucial aspect. While I model currency crises as a dynamic game, Morris and Shin (1999) and Chari and Kehoe (2003) model currency crises as a sequence of one-period games "connected" only through the learning process. As a result, these papers miss part of the dynamic interactions among agents. For example, since in these papers the probability of devaluation in future periods does not affect the game in the current period, backward induction cannot rule out crises that are both predictable and associated with discrete devaluations. Chamley (2003) studies the timing of crises when the exchange rate is constrained within a band as opposed to completely fixed. He shows that this distinction plays an important role since the degree to which the exchange rate appreciates after a failed attack affects the incentives to participate in the attack ex-ante. Chamley's paper is closest to this paper in that it also accounts for dynamic strategic interactions among agents. ${ }^{11}$

An important difference between the model in this paper and others that also analyze the effect

\footnotetext{
${ }^{10}$ Ó Gráda and White (2003) present similar results for the US bank panic of 1857 . They study data on individual depositors at the Emigrant Savings Industrial Bank. They find that "the panic began as a run by the more wealthy and experienced depositors who observed the declining value of bank portfolios [...] others eventually joined them, making 1857 look like a panic generated by asymmetric information." Although this panic was not associated with a currency crisis, its dynamics seem to have been driven by a mechanism similar to the one proposed in this paper.

${ }^{11}$ In the context of asset price bubbles, Abreu and Brunnermeier (2003) show that the uncertainty about the time at which the bubble bursts introduced by private information can delay the bursting of bubbles. Broner (2002) and Rochon (2006) make a similar point in the context of currency crises. In the present paper, the role of private information is more straightforward: when only a fraction of consumers is perfectly informed, discrete devaluations are possible in equilibrium because the amount of reserves available at the time of the attack need only be enough to cover those consumers who can predict the attack.
} 
of private information on the timing of crises is in the set of assumptions necessary to prevent the instantaneous revelation of private information. In general, it is necessary to make some of the following assumptions: exogenous timing of decisions, irreversibility of decisions, discrete action spaces, unobservability of other agents' actions, existence of the right type of "noise." None of these assumptions are necessary in the model presented in this paper. The intuition for this is simple and is due to the fact that informed consumers can predict the timing of the attack. As a result, informed consumers face zero expected losses from devaluation and find it optimal not to adjust their portfolios until the time at which they attack. Since the demand for domestic currency by informed consumers remains constant, uninformed consumers cannot learn anything from observing informed investors portfolios or Central Bank's reserves. ${ }^{12}$ In addition, in this model informed consumers benefit from the fact that uninformed consumers cannot predict the attack on the currency. As a result, they have no incentives to share their private information and, even if they did, they might not be credible.

The paper is organized as follows. In Section 2, I present and solve the model when all consumers are informed $(\alpha=1)$. In Section 3, I solve the model when only a fraction of consumers are informed $(\alpha<1)$. In Section 4, I characterize the set of crisis times which can be sustained in equilibrium in the private information game. In Section 5, I suggest a set of refinement assumptions and analyze the unique "focal" equilibrium. In Section 6, I present some final remarks.

\section{The KFG Model}

I start from a model similar to Krugman (1979) and Flood and Garber (1984) (KFG model). It describes an economy in which a Central Bank maintains a fixed exchange rate but, at the same time, finances the government deficit. Consumers have a demand for real balances that depends negatively on the cost associated with holding domestic currency. Eventually, the Central Bank runs out of international reserves and the peg is abandoned. The model shows when and how this crisis take place.

The Central Bank follows a simple rule: buy and sell foreign currency at a fixed exchange rate.

\footnotetext{
${ }^{12}$ Chari and Kehoe (2004) argue that herd behavior is more likely when the timing of decisions is endogenous because in this case most agents have incentives to move before receiving their signal (due to discounting). As a result, their model and the one in this paper share the feature that the "attack" takes place at a time such that some agents have not received a signal, i.e. are uninformed.
} 
When reserves reach a minimum level of $\bar{R}$, the Central Bank stops intervening in currency markets and the currency is floated. I denote the exchange rate $S_{t}$, which is the domestic currency price of foreign currency. Without loss of generality, the exchange rate $S_{t}$ is assumed to be initially fixed at 1 . I also assume that only domestic consumers hold domestic currency. The law of one price holds and I normalize the foreign price to 1. Thus,

$$
P_{t}=S_{t}
$$

where $P_{t}$ is the domestic price level. The Central Bank's balance sheet is given by

$$
R_{t}=M_{t}-D_{t}
$$

where $M_{t}$ is the nominal money supply and $D_{t}$ is domestic credit. Both before and after the peg is abandoned, the government runs a budget deficit of size $\mu$ in terms of foreign goods. The deficit is fully financed by the Central Bank.

Before the peg is abandoned, the exchange rate is constant, so domestic credit grows at speed $\mu \cdot S_{t}$

$$
\mu=\frac{\dot{D}_{t}}{S_{t}} \text { before the devaluation. }
$$

After the currency is floated, the Central Bank stops intervening in currency markets, reserves remain constant at $\bar{R}$, and as a result monetization of the deficit implies

$$
\mu=\frac{\dot{M}_{t}}{S_{t}} \text { after the devaluation. }
$$

If at some point in time consumers attempt to exchange domestic currency for foreign currency in an amount that exceeds available reserves (in excess of $\bar{R}$ ), reserves are assigned according to a sequential servicing constraint. If the attack on the currency is initiated by a group of consumers, while another group attacks because it observes the attack by the first group, reserves are assigned first to the group that initiated the attack, and then to the group that followed suit.

There is a continuum of mass one of consumers who maximize

$$
U_{t} \equiv E_{t}\left[\int_{t}^{\infty}\left(c_{\tau}+\phi\left(\frac{M_{\tau}}{S_{\tau}}\right)\right) \cdot e^{-\beta \cdot(\tau-t)} \cdot d \tau\right]
$$


where $c$ denotes consumption and $\phi(M / S)$ denotes the liquidity services from holding real money balances. (Recall that $P_{t}=S_{t}$.) I assume $\phi(\cdot), \phi^{\prime}(\cdot)$ are continuous, $\phi(0)=0, \phi^{\prime}(0)=\infty, \phi^{\prime}(\cdot)>0$, and $\phi^{\prime \prime}(\cdot)<0$.

Consumers receive an exogenous, constant, real endowment $y$. They can invest their wealth either in foreign bonds which pay an interest $r=\beta$ or in domestic currency which pays zero interest. There are no transaction costs involved in portfolio changes. I assume that consumers cannot hold negative money balances,

$$
M_{t} \geq 0
$$

In the appendix I show that, under these conditions, consumers' holdings of real balances satisfy the first order condition

$$
\phi^{\prime}\left(\frac{M_{t}}{S_{t}}\right)=r+\pi_{t}^{e}
$$

where $\pi_{t}^{e}$ are the expected losses from devaluation per unit of time. The expected losses from devaluation $\pi_{t}^{e}$ incorporate flow losses due to expected continuous movements in the exchange rate and discrete losses due to unexpected discrete devaluations. At first, one might think that $\pi_{t}^{e}$ should equal the expected rate of devaluation, $-S_{t} \cdot E_{t}\left[d\left(S_{t}^{-1}\right)\right] / d t$. However, this is not the case because the losses associated with discrete devaluations are suffered only on the amount of domestic currency a consumer holds when the peg is abandoned. As a result, the expected losses from devaluation $\pi_{t}^{e}$ depend not only on expected exchange rate movements but also on the probability that a consumer is able to exchange his holdings of domestic currency for foreign currency before reserves are exhausted. ${ }^{13}$

The demand for real balances, which I denote $L(\cdot)$, is then a function of the expected losses from devaluation $\pi_{t}^{e}$ and satisfies

$$
L\left(\pi_{t}^{e}\right) \equiv\left(\phi^{\prime}\right)^{-1}\left(r+\pi_{t}^{e}\right)
$$

where we used the fact that $\phi^{\prime}(\cdot)$ is invertible because $\phi(\cdot)$ is concave. It is easy to show that $L(\cdot)$

\footnotetext{
${ }^{13}$ In the model without private information, this issue can be ignored because in equilibrium the exchange rate is continuous. As we will see, this is not the case in the model with private information. In fact, in that case $\pi_{t}^{e}$ is different for informed and uninformed consumers. Informed consumers can predict the attack on the currency and, thus, are able to get rid of their holdings of domestic currency before the devaluation. As a result, in equilibrium informed consumers face zero expected losses from devaluation until the peg is abandoned.
} 
is continuous, $L(\cdot)>0, L^{\prime}(\cdot)<0, \lim _{\pi_{t}^{e} \rightarrow(-r)^{+}} L\left(\pi_{t}^{e}\right)=\infty$, and $\lim _{\pi_{t}^{e} \rightarrow \infty} L\left(\pi_{t}^{e}\right)=0$.

Consider the possibility that the peg lasts forever. The expected losses from devaluation $\pi_{t}^{e}$ would be always zero, and the money demand would be constant. However, since domestic credit grows at speed $\mu$, a constant money demand and the Central Bank's balance sheet imply that reserves $R_{t}$ would fall at speed $\mu$. Eventually, reserves $R_{t}$ would reach $\bar{R}$ and the peg would be abandoned. The fact that the peg is always eventually abandoned implies that there are two regimes: pre- and post-devaluation. As is usual when analyzing the KFG model, I start by characterizing the equilibrium in the post-devaluation regime and then work backwards.

\section{Post-devaluation regime}

As mentioned above, monetization of the budget deficit during the post-devaluation regime implies

$$
\mu=\frac{\dot{M}_{t}}{S_{t}}
$$

This equation can be rewritten as

$$
\mu=\frac{d}{d t}\left(\frac{M_{t}}{S_{t}}\right)+\frac{\dot{S}_{t}}{S_{t}} \cdot \frac{M_{t}}{S_{t}}=L^{\prime}\left(\pi_{t}^{e}\right) \cdot \dot{\pi}_{t}^{e}+\pi_{t}^{e} \cdot L\left(\pi_{t}^{e}\right)
$$

I now make a number of assumptions customary in the literature. I assume that there are no sunspots and, as a result, the equilibrium in the post-devaluation regime is perfect foresight. I assume that $\mu$ is low enough so that there exist stationary equilibria. And I assume that at the time the peg is abandoned the economy jumps to a stationary equilibrium and, if there is more than one, to the one corresponding to the lowest level of inflation,

$$
\pi^{S} \equiv \min \{\pi: \pi \cdot L(\pi)=\mu\} \cdot^{14}
$$

\footnotetext{
${ }^{14}$ Equation (3) under perfect foresight is equivalent to

$$
\dot{\pi}_{t}=\frac{\mu-\pi_{t} \cdot L\left(\pi_{t}\right)}{L^{\prime}\left(\pi_{t}\right)}
$$

If $\pi_{\tau}<\pi^{S}$, then $\dot{\pi}_{t}<0$ for all $t \geq \tau$. Since $\lim _{\pi \rightarrow(-r)}+L(\pi)=\infty$, then $\lim _{t \rightarrow \infty} \pi_{t}=-r$ and $\lim _{t \rightarrow \infty} L\left(\pi_{t}\right)=\infty$. This possibility can be ruled out because the country would be financing the deficit by running a Ponzi-scheme against the rest of the world. If $\pi_{\tau}>\pi^{S}$, then $\dot{\pi}_{t}>0$ for all $t \geq \tau$ and the economy either diverges into hyperinflation or, if $\pi \cdot L(\pi)=\mu$ has more than one solution, converges to a higher level of inflation. This multiplicity of equilibria in the post-devaluation regime is common to most models in the KFG tradition. Since the focus of this paper is in the
} 
Finally, let us denote the post-devaluation real money balances as

$$
L^{S} \equiv L\left(\pi^{S}\right)
$$

The post-devaluation level of real money balances $L^{S}$ will serve as a "sufficient statistic" for the post-devaluation regime when analyzing the pre-devaluation regime (both under perfect and imperfect information) for two reasons. First, $L^{S}$ is a constant that does not depend on $\bar{R}$ or the time at which the peg is abandoned. Second, it determines, together with post-devaluation nominal balances, the exchange rate that would prevail if the peg were abandoned at time $t$. This shadow exchange rate, which I denote $S_{t}^{S}$, is given by

$$
S_{t}^{S}=\frac{M_{t}^{+}}{L^{S}}=\frac{M_{t}^{-}-\left(R_{t}^{-}-\bar{R}\right)}{L^{S}}=\frac{\bar{R}+D_{t}^{-}}{L^{S}}
$$

where in the second equality I used the fact that nominal money balances would drop by $\left(R_{t}^{-}-\bar{R}\right)$ in case of an attack on the currency that exhausted reserves down to $\bar{R}$, and in the third equality I used the Central Bank's balance sheet and the fact that domestic credit is continuous up to the time when the peg is abandoned.

\section{Pre-devaluation regime}

During the pre-devaluation regime, consumers decide how much domestic currency to hold based on the expected losses from devaluation. At each point in time, they form expectations about the devaluation hazard rate and the size of the devaluation should it take place.

Every consumer knows $\bar{R}$ and the strategies played by the other consumers, so they know at what time, $T(\bar{R})$, the peg will be abandoned. The devaluation hazard rate is thus zero for times before $T(\bar{R})$ and infinite at $T(\bar{R})$. Since $\pi_{t}^{e}=0$ for $t<T(\bar{R})$, consumers hold an amount of domestic currency equal to $L(0)$ until they attack at time $T(\bar{R})$.

Consider first the possibility of an equilibrium in which $T(\bar{R})$ is so late that the shadow exchange rate $S_{T(\bar{R})}^{S}>1$ and the currency suffers a discrete devaluation at $T(\bar{R})$. From Equation (5), we see that after the devaluation consumers would be left with a positive amount of domestic currency

dynamics of the pre-devaluation regime, I do not delve on this issue any further. In any case, as long as the economy always settles on the same post-devaluation equilibrium, the results on the pre-devaluation dynamics do not depend on which one it is. 
$M_{T(\bar{R})}^{+}$. As a result, at time $T(\bar{R})$ consumers would suffer a predictable capital loss of expected size

$$
\frac{M_{T(\bar{R})}^{+}}{L(0)} \cdot\left(1-\frac{1}{S_{T(\bar{R})}^{S}}\right)=\frac{\bar{R}+D_{T(\bar{R})}^{-}}{L(0)} \cdot\left(1-\frac{1}{S_{T(\bar{R})}^{S}}\right)>0
$$

where the first factor is the probability of a consumer not being able to exchange his holdings of domestic currency before reserves reach $\bar{R}$ and the peg is abandoned. ${ }^{15}$ This cannot happen in equilibrium since consumers would have an incentive to deviate and attack the currency before time $T(\bar{R})$.

Consider next the possibility of an equilibrium in which $T(\bar{R})$ is so early that the shadow exchange rate $S_{T(\bar{R})}^{S}<1$ and the currency suffers a discrete revaluation at $T(\bar{R})$. This cannot happen in equilibrium since consumers would have an incentive to deviate and not attack the currency at $T(\bar{R})$.

As a result, in equilibrium $T(\bar{R})$ must satisfy $S_{T(\bar{R})}^{S}=1$ so that the exchange rate is continuous at $T(\bar{R})$. From Equation (5), we get

$$
S_{T(\bar{R})}^{S}=1=\frac{M_{T(\bar{R})}^{-}-\left(R_{T(\bar{R})}^{-}-\bar{R}\right)}{L^{S}} \Rightarrow M_{T(\bar{R})}^{-}-R_{T(\bar{R})}^{-}=L^{S}-\bar{R} \Rightarrow D_{T(\bar{R})}^{-}=L^{S}-\bar{R} .
$$

At time $T(\bar{R})$, consumers attack the currency by reducing their holdings of domestic currency from $L(0)$ to $L^{S}$. This portfolio reallocation is in response to the higher opportunity cost of holding domestic currency in the post devaluation regime. It is easy to check that the size of this portfolio reallocation equals the drop in reserves at the Central Bank by noting that Equation (6) can be rewritten as

$$
L(0)-L^{S}=R_{T(\bar{R})}^{-}-\bar{R},
$$

since $M_{T(\bar{R})}^{-}=L(0)$. Before the peg is abandoned domestic credit $D_{t}$ increases continuously and monotonically, so Equation (6) holds for a single time $T(\bar{R})$ and the equilibrium is unique.

The analysis of the model in this section has been standard, and so are the results. Although the peg is abandoned in response to an attack that wipes out the Central Bank's reserves (down

\footnotetext{
${ }^{15}$ This expected capital loss is correct if all consumers attempt to exchange all their holdings of domestic currency at time $T(\bar{R})$. It is easy to show that if this were not the case, then the expected capital loss would be even larger for some consumers.
} 
to $\bar{R}$ ), the timing of the attack is predictable and the exchange rate is continuous.

Under a more general interpretation of the model, the assumption that consumers have perfect information about $\bar{R}$ would correspond to the assumption that all consumers are perfectly informed about the willingness and capability of the Central Bank to defend the peg. Apart from being unrealistic, this assumption is far from innocuous. In the next section I show that the results change dramatically when it is relaxed.

\section{Private information}

In this section, I generalize the KFG model by relaxing the assumption that all consumers know $\bar{R}$. As discussed in the introduction, it seems reasonable that some consumers have access to additional sources of information that allow them to estimate quite precisely the willingness or capability of the Central Bank to defend the peg. This information includes off-balance sheet transactions and access to additional lines of credit by the Central Bank, the health of the financial system, inside information about politicians objectives or strategies, etc. The rest of the consumers, on the other hand, are likely to only have access to public information, which provides a less precise signal about when the peg will be abandoned. The information structure is summarized in the following assumption. $^{16}$

Assumption 1. A fraction $\alpha$ of informed consumers knows $\bar{R}$. A fraction $(1-\alpha)$ of uninformed consumers knows that $\bar{R}$ is drawn from a probability distribution with density $g(\cdot)$ and support $\left[0, R_{M}\right] . g(\cdot)$ has no atoms, is continuous on $\left[0, R_{M}\right]$, and is common knowledge. $G(\cdot)$ is the cumulative distribution of $g(\cdot)$. (Note that the KFG model corresponds to the special case in which $\alpha=1$.

The post-devaluation regime of the game under private information is identical to the one under perfect information, since in the aftermath of the attack $\bar{R}$ becomes common knowledge. As a result, the holdings of real balances after the devaluation are still equal to $L^{S}$. The predevaluation regime under private information, on the other hand, has two crucial differences with

\footnotetext{
${ }^{16} \mathrm{It}$ is not necessary to assume that $\alpha$ is perfectly known. It can be shown that in a model in which both informed and uninformed consumers only know that $\alpha \in\left[\alpha_{\min }, \alpha_{\max }\right]$ the equilibria are similar to those in the current model when $\alpha=\alpha_{\max }$.
} 
respect to the one under perfect information: there are multiple equilibria; and the exchange rate is, in general, discontinuous at the time of the attack.

The demand for real balances by each consumer is still given by Equation (2). However, informed and uninformed consumers in general hold different amounts of real balances because they face different expected losses from devaluation $\pi_{t}^{e} \cdot{ }^{17}$ Informed consumers know the threshold level of reserves $\bar{R}$ and, in equilibrium, the strategy played by every other consumer. ${ }^{18}$ As a result, they know at what time $T(\bar{R})$ the peg will be abandoned. Since informed consumers know that there will not be a devaluation before time $T(\bar{R})$, in equilibrium they hold an amount of domestic currency equal to $L(0)$ for all previous times. To avoid losses from devaluation, at time $T(\bar{R})$ informed consumers attempt to exchange all their holdings of domestic currency. If $R_{T(\bar{R})}^{-}-\bar{R} \leq \alpha \cdot L(0)$, the attack is large enough to cause the abandonment of the peg; otherwise, uninformed consumers follow suit and attack the currency until reserves reach $\bar{R}$ and the peg is abandoned.

After the peg is abandoned, uninformed consumers still hold excess real balances and thus continue selling domestic currency, although to informed consumers instead of the Central Bank. The exchange rate at which uninformed consumers sell domestic currency to informed consumers equals the shadow exchange rate $S_{t}^{S} \geq 1$, determined as the price that clears the market for domestic currency in the post-devaluation regime. In other words, the amount and price of domestic currency involved in this transaction is given by the condition that, ex-post, both types of consumers hold an amount $L^{S}$ of real money balances, as described in Section 2.

The dynamics of the game are determined by the strategies played by informed consumers during the pre-devaluation regime. Let $T_{i}(\bar{R})$, where $i \in[0, \alpha]$, denote the time at which informed consumer $i$ attacks the currency given that the threshold level of reserves is $\bar{R}$. It is easy to show that, in equilibrium, all informed consumers play the same strategy.

Lemma 1. In equilibrium, all informed consumers play the same strategy, i.e. $T_{i}(\cdot)=T_{j}(\cdot)$ for all $i, j \in[0, \alpha]$.

Proof. Assume that a partial attack by informed consumers takes place. If the attack leads to a devaluation, those informed consumers that did not participate in the attack suffer a predictable

\footnotetext{
${ }^{17}$ Allowing consumers to short the domestic currency would not affect qualitatively the results of the paper, as long as they could not do so by an infinite amount. Short selling would have the same effect as increasing the fraction of informed consumers $\alpha$.

${ }^{18}$ Uninformed consumers also know the strategies played by informed consumers, but this is not enough to predict their actions since these actions depend on the unobserved threshold level of reserves $\bar{R}$.
} 
capital loss. If the attack does not lead to a devaluation, those informed consumers that participated in the attack unnecessarily reduced their holdings of domestic currency. Neither can occur in equilibrium.

As a result, we will denote $T(\bar{R})$ the (common) time at which all informed consumers attack the currency if the threshold level of reserves equals $\bar{R} \cdot{ }^{19}$

We now calculate uninformed consumers' expected losses from devaluation $\pi_{t}^{e}$, which depend on $T(\cdot)$. Since there can be more than one threshold level of reserves $\bar{R}$ that leads to an attack at time $T, T(\cdot)$ need not be one to one. As a result, the shadow exchange rate as a function of time is not well defined. However, we can define an analogous shadow exchange rate as a function of $\bar{R}$. From the Central Bank's balance sheet, post devaluation nominal balances $M_{t}^{+}=\bar{R}+D_{t}^{-}$and, as a result, the post-devaluation exchange rate $S_{t}^{+}=\left(\bar{R}+D_{t}^{-}\right) / L^{S}$. We thus define the shadow exchange with respect to $\bar{R}$ as

$$
S_{\bar{R}}^{S}=\frac{\bar{R}+D_{T(\bar{R})}^{-}}{L^{S}}
$$

We first calculate the expected losses during a finite time interval $[t, t+\nu)$ and then take the limit as $\nu \rightarrow 0$. Let

$$
G^{\geq}(\bar{R})=\int_{\left\{\bar{R}^{\prime}: T\left(\bar{R}^{\prime}\right) \geq T(\bar{R})\right\}} g\left(\bar{R}^{\prime}\right) \cdot d \mu
$$

be the ex-ante probability that the attack takes place at or after $T(\bar{R}) .{ }^{20}$

Let $L_{t}^{U}$ denote holdings of real balances by an uninformed consumer at time $t$ conditional on no attack before time $t$. The probability of an uninformed consumer not being able to exchange his holdings of domestic currency before the peg is abandoned equals

$$
\frac{\bar{R}+D_{T(\bar{R})}^{-}}{(1-\alpha) \cdot L_{T(\bar{R})}^{U}},
$$

because the amount of domestic currency that cannot be exchanged before the peg is abandoned equals $M_{T(\bar{R})}^{+}=\bar{R}+D_{T(\bar{R})}^{-}$, informed consumers never suffer devaluation losses, and domestic currency holdings by uninformed consumers at the time of the attack equal $(1-\alpha) \cdot L_{T(\bar{R})}^{U}$.

\footnotetext{
${ }^{19}$ The function $T(\cdot)$ can be quite general. We only impose the technical restriction that $T(\cdot)$ be measurable, to be able to calculate uninformed consumers' expected losses from devaluation.

${ }^{20}$ Note that if $T(\cdot)$ is monotonic decreasing, $G^{\geq}(\cdot) \equiv G(\cdot)$.
} 
As a result, the expected losses from devaluation by uninformed consumers during $t \in[t, t+\nu)$ are given by

$$
\Pi^{e}(t, \nu)=\int_{\{\bar{R}: T(\bar{R}) \in[t, t+\nu)\}}\left(1-\frac{1}{S_{\bar{R}}^{S}}\right) \cdot\left(\frac{\bar{R}+D_{T(\bar{R})}^{-}}{(1-\alpha) \cdot L_{T(\bar{R})}^{U}}\right) \cdot \frac{g(\bar{R})}{G^{\geq}(\bar{R})} \cdot d \mu
$$

where the integral is taken over all $\bar{R}$ such that the attack takes place during $t \in[t, t+\nu)$. The first factor inside the integral equals the size of the devaluation and the second factor equals the probability that any given uninformed consumer suffers the associated loss.

Finally, the expected losses from devaluation by uninformed consumers at time $t$ are given by

$$
\pi_{t}^{e}=\lim _{\nu \rightarrow 0} \frac{\Pi^{e}(t, \nu)}{\nu}
$$

Let

$$
\bar{R}(t)=\{\bar{R}: T(\bar{R})=t\}
$$

be the set of $\bar{R}$ such that the attack by informed consumers takes place at $t$.

Proposition 1. In all equilibria of the game, the strategies of informed and uninformed consumers are characterized by two functions: $T(\bar{R})$ denotes the time at which informed consumers attack the currency as a function of the threshold level of reserves $\bar{R} ; L_{t}^{U}$ denotes money holdings by uninformed consumers during the pre-devaluation regime. Furthermore, the functions $T(\bar{R})$ and $L_{t}^{U}$ correspond to an equilibrium of the game if and only if the following conditions are satisfied for all $t$ and all $\bar{R} \in \bar{R}(t)$ :

$$
\begin{aligned}
& \text { (i) } L_{t}^{U}=L\left(\pi_{t}^{e}\right), \\
& \text { (ii) } \bar{R} \geq L^{S}-D_{t}, \\
& \text { (iii) } \bar{R} \leq(1-\alpha) \cdot L_{t}^{U}-D_{t} \text { if } \bar{R}>L^{S}-D_{t},
\end{aligned}
$$

where $\pi_{t}^{e}$ and $\bar{R}(t)$ are as defined above.

Proof. That consumers strategies are characterized by functions $T(\bar{R})$ and $L_{t}^{U}$ follows from Lemma (1) and the fact that all uninformed consumers face the same maximization problem which has a unique solution. Condition (i) corresponds to maximization by uninformed consumers. It follows from the 
first order condition for uninformed consumers and the definition of $L(\cdot)$ in Equation (2). Conditions (ii) and (iii) correspond to maximization by informed consumers. Condition (ii) states that informed consumers would not attack the currency so early that a revaluation takes place, since in that case an individual informed consumer would prefer not to attack and receive the capital gains associated with the revaluation. The condition is equivalent to $S_{\bar{R}}^{S} \geq 1$ (see Equation (7)). Condition (iii) states that if the attack is expected to lead to a discrete devaluation (Condition (ii) satisfied strictly), it cannot take place so late that Central Bank reserves are not enough to cover all informed consumers. If it did, an individual informed consumer would attack earlier to avoid suffering discrete capital losses with positive probability.

\section{Equilibrium crisis times}

In this section, I analyze the set of times at which the crisis can take place, in equilibrium, as a function of the fraction of informed consumers $\alpha$ who know the threshold level of reserves $\bar{R}$. The results are summarized in Figure 1, which shows the times at which the attack by informed consumers can take place for a given level of $\bar{R}$. I will show that the KFG equilibrium of zero devaluation in the perfect information game is also an equilibrium of the private information game. In addition, when the fraction of informed consumers $\alpha$ is high enough, the KFG equilibrium of zero devaluation is unique. However, when the fraction of informed consumers $\alpha$ is low, there are other equilibria in which the peg lasts longer, giving rise to discrete devaluations.

Let $T_{\alpha}(\bar{R})$ be the set of possible crisis times when the threshold level of reserves equals $\bar{R}$ and the fraction of informed consumers equals $\alpha$. In other words,

$$
T_{\alpha}(\bar{R})=\{T: \exists \text { an equilibrium of } \alpha \text {-game such that } T(\bar{R})=T\}
$$

The following proposition characterizes $T_{\alpha}(\bar{R})$ and shows that the bifurcation diagram of the game is given by the shaded area in the top panel of Figure 1.

Proposition 2. Let $\alpha^{*}=\left(L(0)-L^{S}\right) / L(0)$. The set of possible crisis times $T_{\alpha}(\bar{R})$ is given by

$$
T_{\alpha}(\bar{R})= \begin{cases}\left\{T_{K F G}(\bar{R})\right\} & \text { if } \alpha \in\left[\alpha^{*}, 1\right] \\ {\left[T_{K F G}(\bar{R}), T_{K F G}(\bar{R})+\mu^{-1} \cdot \min \left\{\left(\alpha^{*}-\alpha\right) \cdot L(0), \bar{R}\right\}\right]} & \text { if } \alpha \in\left(0, \alpha^{*}\right)\end{cases}
$$


Proof. The proposition follows from the following five properties of $T_{\alpha}(\bar{R})$ :

(i) For all $\alpha \in(0,1]$, there exists a KFG equilibrium in which $T(\bar{R})=T_{K F G}(\bar{R})$.

(ii) For all $\alpha \in(0,1]$ and all equilibria, $T(\bar{R}) \geq T_{K F G}(\bar{R})$.

(iii) For all $\alpha \in\left[\alpha^{*}, 1\right]$, the KFG equilibrium is unique.

(iv) For all $\alpha \in\left(0, \alpha^{*}\right)$ and all equilibria,

$$
T(\bar{R}) \leq T_{K F G}(\bar{R})+\mu^{-1} \cdot \min \left\{\left(\alpha^{*}-\alpha\right) \cdot L(0), \bar{R}\right\}
$$

(v) For all $\alpha \in\left(0, \alpha^{*}\right)$ and all $T^{\prime}$ such that

$$
T^{\prime} \in\left[T_{K F G}(\bar{R}), T_{K F G}(\bar{R})+\mu^{-1} \cdot \min \left\{\left(\alpha^{*}-\alpha\right) \cdot L(0), \bar{R}\right\}\right]
$$

there exists an equilibrium such that the crisis takes place at $T(\bar{R})=T^{\prime}$.

Although a formal proof of these properties can be found in the appendix, I provide here an informal discussion. (i) If an informed consumer expected other informed consumers to attack at time $T_{K F G}(\bar{R})$, he would also expect uninformed consumers to respond instantaneously and cause the peg to be abandoned at $T_{K F G}(\bar{R})$, leading to an immediate increase in the inflation rate. As a result, he would also attack at time $T_{K F G}(\bar{R})$. (ii) Informed consumers would not attack if they expected a revaluation. (iii) When $\alpha \in\left[\alpha^{*}, 1\right]$, the total amount of domestic currency held by informed consumers $\alpha \cdot L(0)$ is at least as high as the total portfolio reallocation that takes place at the time of the attack, which equals at most $L(0)-L^{S}$. As a result, there are not enough reserves at the Central Bank to cover all informed consumers even at time $T(\bar{R})=T_{K F G}(\bar{R})$. Thus, if the crisis involved a discrete devaluation informed consumers would suffer predictable capital losses, which cannot happen in equilibrium. (iv) and (v) When $\alpha \in\left(0, \alpha^{*}\right)$, the total amount of domestic currency held by informed consumers $\alpha \cdot L(0)$ is lower than the total portfolio reallocation that takes place at the time of the devaluation in the KFG equilibrium, $L(0)-L^{S}$. This opens a "wedge" between Conditions (ii) and (iii) in Proposition (1): for low $\alpha$ there are equilibria in which Central Bank reserves are high enough to cover all informed consumers even if the attack takes place so late that it leads to a devaluation. As shown in the appendix, the extreme case of $T(\bar{R})=T_{K F G}(\bar{R})+\mu^{-1} \cdot \min \left\{\left(\alpha^{*}-\alpha\right) \cdot L(0), \bar{R}\right\}$ corresponds to the latest time at which the crisis can take place and still have enough reserves at the Central Bank to cover informed consumers. 
Intuitively, when $\alpha<\alpha^{*}$ it is possible to think of equilibria as differing in the propensity of informed consumers to attack the currency. At one extreme, in the KFG equilibrium informed consumers attack the currency as soon as the attack is not expected to lead to a revaluation. This is the only equilibrium that does not involve discrete devaluations. At the other extreme, informed consumers wait until there are just enough reserves left for them, and nothing left for uninformed consumers. As the fraction of informed consumers $\alpha$ decreases, so does the size of the attack by informed consumers, naturally shifting the second extreme towards later times. As a result, the size of the largest possible devaluation increases when the fraction of informed consumers $\alpha$ decreases. In addition, every crisis time between these two extremes can be sustained in equilibrium.

I have shown that some important conclusions from previous first generation models hinged on the implicit assumption of perfect information. In particular, the result that crisis should take place at the time at which the shadow exchange rate equals the peg and, thus, be predictable and not involve discrete devaluations is not robust to the inclusion of private information. While it is true that abandoning the peg at the time at which the shadow exchange rate equals the peg $\left(T(\bar{R})=T_{K F G}(\bar{R})\right)$ is always an equilibrium, it is only one of many possible equilibria when the fraction of informed consumers $\alpha$ is lower than the threshold level $\alpha^{*}$. In all other equilibria, the crisis takes place at a time $T(\bar{R})>T_{K F G}(\bar{R})$ and involves a discrete devaluation.

The existence of multiple equilibria implies that, even if one knew $\bar{R}$, it would not be possible to predict the timing of the attack without knowing which equilibrium is being played. Since fundamentals deteriorate over time, the range of possible crisis times $T_{\alpha}(\bar{R})$ is associated with a corresponding range of crisis fundamentals, which in this model corresponds to a range of crisis levels for domestic credit, $D_{\alpha}(\bar{R}) \equiv\left[D_{\alpha}^{\min }(\bar{R}), D_{\alpha}^{\max }(\bar{R})\right]$. The model implies that the attack cannot take place when domestic credit is bellow $D_{\alpha}^{\min }(\bar{R})$, while it will have taken place for sure by the time domestic credit is above $D_{\alpha}^{\max }(\bar{R})$. For intermediate levels, the occurrence of the attack depends on the particular equilibrium being played. These results parallel those in the second generation literature, in which there exist some levels of fundamentals for which attacking the currency is the unique equilibrium, some levels of fundamentals for which not attacking the currency is the unique equilibrium, and intermediate levels for which there are multiple equilibria. Interestingly, the model has novel predictions regarding the variables that influence the degree of equilibrium indeterminacy, as measured by $D_{\alpha}^{\max }(\bar{R})-D_{\alpha}^{\min }(\bar{R})$. In particular, it is easy to show that $D_{\alpha}^{\max }(\bar{R})-D_{\alpha}^{\min }(\bar{R})$ is 
increasing in the difference between $\bar{R}$ and the minimum possible $\bar{R}$ (which is zero in this case), is decreasing in the fraction of informed consumers $\alpha$, and is increasing in the drop in money demand $L(0)-L^{S}$, which in turn is increasing in the budget deficit $\mu$ and in the elasticity of money demand.

\section{A unique equilibrium}

The structure of equilibria characterized by Proposition (2) shows that the set of equilibria is, in general, very large. First, the function that determines the time of attack by informed consumers as a function of the threshold level of reserves, $T(\bar{R})$, need not be monotone. In other words, there can be equilibria in which the attack takes place sooner when the Central Bank is willing to use more of its reserves to defend the currency. Second, as mentioned above equilibria may differ in the propensity of informed consumers to attack the currency. At one extreme, in the KFG equilibrium the attack takes place at a time when a sizable amount of reserves is left for uninformed consumers after the initial attack by informed consumers. At the other extreme, the attack takes place at a time such that the amount of reserves available to defend the currency is equal to the size of the attack by informed consumers. Third, the image of $T(\bar{R})$ need not be dense; namely, there can be periods of "tranquility" in which uninformed consumers know that the probability of an attack by informed consumers is zero, followed by periods in which attacks are possible, and so forth.

In this section, I provide a set of refinement assumptions that narrows the set of equilibria to those that seem most likely to be played. First, I assume that the stronger the willingness of the Central Bank to defend the peg, the longer the peg lasts. ${ }^{21}$

Refinement 1 (Monotone strategies). I assume that the function $T(\bar{R})$ is monotone decreasing. Namely, if $\bar{R}_{1}>\bar{R}_{2}, T\left(\bar{R}_{1}\right) \leq T\left(\bar{R}_{2}\right)$.

Second, I assume that consumers cannot react to the actions of other consumers instantaneously. The existence of a positive lag may be rationalized by assuming that there is a small cost associated with monitoring other consumers' actions, so constant monitoring is impossible.

\footnotetext{
${ }^{21}$ There is no formal justification for this assumption, but it seems reasonable to expect that consumers will not focus on an equilibrium in which they attack sooner when fundamentals are stronger. A similar monotonicity assumption is made by Abreu and Brunnermeier (2003) in their analysis of bubbles. When defining a trading equilibrium, they assume that the earlier a trader becomes aware of the bubble, the earlier he sells his stocks.
} 
Refinement 2 (Delayed response). I assume that the game is the limit, as $\varepsilon \rightarrow 0$, of the game in which consumers observe other consumers' actions with a positive lag of $\varepsilon$, so that they can condition their portfolio decisions at time $t$ on other consumers' actions up to time $t-\varepsilon$.

Third, I assume that there is some degree of collusion among informed consumers. The simplest way of introducing market power is by assuming that one of the informed consumers is not infinitesimal.

Refinement 3 (Non-infinitesimal informed consumer). I assume that the game is the limit, as $\delta \rightarrow 0$, of the game in which one of the informed consumers is of size $\delta$, while all the others are infinitesimal.

The aim of this section is to characterize the set of equilibria that survive these refinements. It is natural and instructive to start by analyzing whether the KFG equilibrium belongs to this set, since it is the only equilibrium that has been studied in the literature up to this point.

Lemma 2. The KFG equilibrium survives the refinements if and only if $\alpha \geq \alpha^{*}$, i.e. if and only if it is the unique equilibrium of the game.

Proof. The KFG equilibrium always satisfies Refinement (1). Refinement (2) is satisfied if $\alpha \geq \alpha^{*}$ because the size of the attack by informed consumers is large enough to cause the abandonment of the peg, so the fact that uninformed consumers respond with a lag is irrelevant. If $\alpha<\alpha^{*}$, on the other hand, Refinement (2) is not satisfied. Consider the incentives to deviate by an informed consumer. Starting from the equilibrium, an informed consumer knows that after the other informed consumers attack the currency at $T_{K F G}(\bar{R})$ the peg will survive until uninformed consumers follow suit. When the response time is zero, there are no incentives to deviate because uninformed consumers respond immediately and the peg is abandoned at $T_{K F G}(\bar{R})$. When the response time is $\varepsilon>0$, on the other hand, the peg survives until $T_{K F G}(\bar{R})+\varepsilon$. So an informed consumer would have an incentive to deviate and wait until, for example, $T_{K F G}(\bar{R})+\varepsilon / 2$. He would receive the flow benefit of holding $L(0)$ instead of $L^{S}<L(0)$ during an additional length of time $\varepsilon / 2$ without suffering devaluation losses. Refinement (3) is satisfied if $\alpha \geq \alpha^{*}$, because the peg is abandoned at $T_{K F G}(\bar{R})$ regardless of whether the non-infinitesimal consumer participates.

As argued above, the KFG equilibrium corresponds to the extreme case in which the attack takes place as early as possible, consistent with the attack not leading to a revaluation. When $\alpha<\alpha^{*}$, 
this time is such that the size of the attack by informed consumers is not enough to cause the abandonment of the peg. As the proof of Lemma (2) shows, as long as uninformed consumers cannot respond immediately such an outcome is not an equilibrium. ${ }^{22}$ In fact, an argument analogous to that in the proof of Proposition (2) shows that in any equilibrium that survives Refinement (2) the amount of domestic currency exchanged for foreign currency by informed consumers at the time of the attack cannot be smaller than the size of the attack necessary to bring down the peg. In other words,

$$
\alpha \cdot L(0) \geq R_{T(\bar{R})}^{-}-\bar{R}
$$

and the following lemma follows:

Lemma 3. Any equilibrium that survives Refinement (2) satisfies the following condition (in addition to Conditions (i), (ii), and (iii) in Proposition (1)):

$$
\text { (iv) } \quad \bar{R} \geq(1-\alpha) \cdot L_{T(\bar{R})}^{U}-D_{T(\bar{R})}
$$

Proof. The result follows immediately from Equation (10), the Central Bank's balance sheet, and the fact that $M_{t}=\alpha \cdot L(0)+(1-\alpha) \cdot L_{t}^{U}$ during the pre-devaluation regime.

Lemma (3) states that when uninformed consumers react with a positive lag, informed consumers delay their attack until a time such that there are no reserves left for uninformed consumers. Together with Condition (iii) in Proposition (1), it also implies that if informed consumers anticipate a discrete devaluation, then the attack takes place at a time such that available reserves are just enough to cover the attack by informed consumers. Intuitively, the equilibria that are likely to be played are at the other extreme from the KFG equilibrium, in which the attack takes place as soon as possible. This highlights the intrinsic implausibility of the KFG equilibrium: why should one expect informed consumers to attack at a time at which there are plenty of reserves, instead of waiting and benefiting from higher real balances at no cost? In the KFG equilibrium this is possible only because of a total lack of coordination among informed consumers and the fact that uninformed consumers can react instantaneously.

\footnotetext{
${ }^{22}$ Note that under Refinement (2) both informed and uninformed consumers observe other consumers' actions with a lag. However, this restriction is not binding for informed consumers since they do not need to observe other consumers' actions to know the crisis time.
} 
The following lemma states that if at some point in time the crisis hazard rate is positive, it remains positive until the crisis takes place. It thus rules out equilibria in which there are periods of temporary "tranquility."

Lemma 4. In equilibrium, $\exists\left[t_{0}, t_{1}\right]$ such that the function that determines the time of attack $T$ : $\left[0, R_{M}\right] \rightarrow\left[t_{0}, t_{1}\right]$ is a continuous, strictly decreasing function of $\bar{R}$. In addition, $T(0)=t_{1}$ satisfies $S_{T(0)}^{S}=1$.

Proof. See appendix.

The intuition behind the lemma is simple. Assume there exists some time $t$ at which the attack hazard goes from positive to zero. At time $t$, the demand for real balances by uninformed consumers is expected to increase. If the threshold level of reserves $\bar{R}$ where such that the attack by informed consumers takes place right before $t$, the non-infinitesimal informed consumer would have an incentive to postpone his attack by, say, $\varepsilon / 2$. By doing so, he would enjoy high real balances for longer, and still be able to exchange his holdings of domestic currency before reserves are exhausted, since uninformed consumers would increase their holdings of domestic currency at $t$ before realizing that the attack took place.

The fact that $T(\bar{R})$ is a strictly monotonic function considerably simplifies the analysis. Let $\bar{R}_{t}$ be the inverse of $T(\bar{R})$. From Equation (8), the expected losses from devaluation between $t$ and $t+\nu$ are given by

$$
\Pi^{e}(t, \nu)=\int_{\bar{R}_{t+\nu}}^{\bar{R}_{t}}\left(1-\frac{1}{S_{\bar{R}}^{S}}\right) \cdot \frac{g(\bar{R})}{G\left(\bar{R}_{t}\right)} \cdot d \bar{R},
$$

where I have used Condition (iv), which implies there will not be any reserves left for uninformed consumers after informed consumers attack. From Equation (9), the expected losses from devaluation at time $t$ are given by

$$
\pi_{t}^{e}=\lim _{\nu \rightarrow 0} \frac{\Pi^{e}(t, \nu)}{\nu}=\frac{g\left(\bar{R}_{t}\right)}{G\left(\bar{R}_{t}\right)} \cdot\left(-\dot{\bar{R}}_{t}\right) \cdot\left(1-\frac{1}{S_{\bar{R}_{t}}^{S}}\right) .
$$

Equation (11) states that the expected losses from devaluation equal the attack hazard rate multiplied by the size of the devaluation conditional on an attack taking place. Uninformed consumers' knowledge of $\bar{R}$ starts at the unconditional distribution $g(\cdot)$. As reserves drop and the attack by informed consumers does not take place, uninformed consumers learn that $\bar{R}$ is smaller than the 
threshold level that would have lead to an earlier attack. As a result, the conditional density of $\bar{R}$ equals $g\left(\bar{R}_{t}\right) / G\left(\bar{R}_{t}\right)$. The attack hazard rate equals this conditional density multiplied by the speed at which $\bar{R}_{t}$ decreases.

From the First Order Condition (1) applied to uninformed consumers, we obtain

$$
\pi_{t}^{e}=\phi^{\prime}\left(L_{t}^{U}\right)-r
$$

The following proposition follows from Differential Equation (11), Equation (7), Conditions (iii) and (iv), Equation (12), and the boundary condition from Lemma (4):

Proposition 3. There is a unique equilibrium to the private information game which survives Refinements (1), (2), and (3). For $\alpha \geq \alpha^{*}$ this unique equilibrium is the KFG equilibrium described above. For $\alpha<\alpha^{*}$, this unique equilibrium is characterized by the function $\bar{R}_{t}$ which denotes the threshold level of reserves $\bar{R}$ such that the attack takes place at $t$. The function $\bar{R}_{t}$ satisfies the differential equation

$$
\dot{\bar{R}}_{t}=-\frac{G\left(\bar{R}_{t}\right)}{g\left(\bar{R}_{t}\right)} \cdot\left(\frac{\bar{R}_{t}+D_{t}}{\bar{R}_{t}+D_{t}-L^{S}}\right) \cdot\left(\phi^{\prime}\left(\frac{\bar{R}_{t}+D_{t}}{1-\alpha}\right)-r\right)
$$

and boundary condition

$$
\bar{R}_{T(0)}=0,
$$

where $T(0)$ is given by the condition $D_{T(0)}^{-}=L^{S}$ (which is equivalent to $\left.S_{T(0)}^{S}=1\right)$.

Proposition (3) shows that, among the range of equilibrium crisis times characterized in Section 4, there is a single "focal" one that is consistent with an environment in which worse fundamentals lead to earlier crises times, investors do not monitor constantly other investors' actions, and informed investors have some ability to collude. In addition, the unique equilibrium which survives the refinements involves a discrete devaluation when the fraction of informed consumers is low.

To illustrate the characteristics of this unique equilibrium, Figure 2 describes the behavior of several variables during the onset of a crisis. The six panels show $\bar{R}_{t}$, the unconditional probability density of attack, the conditional devaluation $1-\left(S_{t}^{S}\right)^{-1}$, the expected devaluation losses $\pi_{t}^{e}$, the 
money demand by uninformed consumers $(1-\alpha) \cdot L_{t}^{U}$, and reserves $R_{t}$. I show the behavior of these variables for the focal equilibrium of three economies that differ in the proportion of informed consumers $\alpha$.

When $\alpha$ is just lower than $\alpha^{*}$, the equilibrium is very similar to the KFG equilibrium. The holdings of domestic currency by informed consumers $\alpha \cdot L(0)$ are close to the size of the attack required to bring reserves down to $\bar{R}$, even at times close to $T_{K F G}(\bar{R})$. The size of the devaluation and the expected devaluation losses are small and, as a result, $(1-\alpha) \cdot L_{t}^{U} \approx(1-\alpha) \cdot L(0)$ throughout. ${ }^{23}$

When the fraction of informed consumers $\alpha$ is low, on the other hand, informed consumers delay their attack, since they know that only a small fraction of consumers can anticipate when the attack will take place. As a result, the size of the devaluation and the expected devaluation losses are large. This is reflected in an early fall in money demand by uninformed consumers and a corresponding early fall in reserves. A low fraction of informed consumers $\alpha$ is thus associated with delayed crises, larger devaluations, lower reserves in the run-up to the attack, and a smaller drop in reserves at the time of the attack itself.

\section{Final remarks}

This paper proposes a simple modification to the standard first generation model of currency crisis, by relaxing the assumption that all consumers are perfectly informed about the level of fundamentals. This modification fundamentally affects the nature of equilibria and the predictions of the model.

The model with private information can account for a number of stylized facts that are inconsistent with previous first generation models. First, currency attacks can be unpredictable. This unpredictability arises not only from the multiplicity of equilibria but also from the fact that, even if an observer knew which equilibrium is being played, he would be unable to predict the timing of the attack based solely on public information. Second, currency attacks can lead to discrete devaluations. In previous first generation models discrete devaluations could be ruled out because all consumers were both rational and perfectly informed and, thus, could not suffer capital losses

\footnotetext{
${ }^{23}$ The "continuity" of the focal equilibrium as a function of $\alpha$ for $\alpha \approx \alpha^{*}$ also follows from Property (iii) of Proposition (2), which applies to all equilibria.
} 
in equilibrium. When a fraction of consumers is not perfectly informed, on the other hand, currency attacks can lead to discrete devaluations in equilibrium. The reason is that while informed consumers can predict the timing of the attack, it is uninformed consumers who suffer the capital losses associated with the devaluation. ${ }^{24}$

The model has a number of novel empirical predictions. Most importantly, it predicts that the larger the amount of private information (lower $\alpha$ ), the more the attack on the currency is delayed, leading to larger discrete devaluations. This result can be understood as saying that, conditional on the behavior of fundamentals, transparency accelerates the attack on the currency. ${ }^{25}$ Under the assumption that policies in developed countries are more transparent than in emerging markets, this result can account for the fact that currency crises are usually more severe in emerging markets.

There are, at least, two interesting directions in which the model could be extended. First, what would be the effect of introducing long-term assets? Preliminary work suggests that this effect depends on how easily informed consumers can resell these assets before the devaluation. When long-term assets can be easily resold, their price does not reflect informed consumers' private information and the dynamics of crises are not qualitatively affected. ${ }^{26}$ When long-term assets cannot be easily resold, on the other hand, their existence may accelerate the devaluation. ${ }^{27}$ Second, what would be the effect of allowing for a more active Central Bank? Lahiri and Végh (2003) and Flood and Jeanne (2005) show that raising interest rates can delay or even avoid devaluations in models similar to the one in this paper but without private information. Broner (2002), using a more reduced-form model, suggests that interest-rate defenses are more effective in the presence of private information.

\footnotetext{
${ }^{24}$ Although the model can only account for uncertainty about the time at which the peg is abandoned, it can be easily modified so that it can also account for uncertainty about whether the peg is abandoned or not. This can be done by adding a "fiscal reform hazard rate" as Rigobon (2002) does in his analysis of inflation stabilization programs.

${ }^{25}$ This result contrasts with Morris and Shin (1998), who find that transparency increases the likelihood of a currency crisis for relatively strong fundamentals, while it decreases it for relatively weak fundamentals.

${ }^{26}$ In this case, if informed consumers are the marginal buyers of long-term assets the devaluation premium is zero, while if uninformed consumers are the marginal buyers of long-term assets the devaluation premium only reflects public information. In either case, the price of long-term assets does not reflect informed consumers' private information.

${ }^{27}$ Under what conditions would informed consumers be able to easily resell long-term assets? Consider two cases: (i) The Central Bank is willing to spend reserves to purchase not only domestic currency but also other assets denominated in domestic currency. Examples include Central Banks spending reserves to keep banks afloat or more directly intervening in the market for domestic assets (such as when the Central Bank of Hong Kong spent reserves to purchase domestic equities in 1998). (ii) Long-term assets trade in anonymous and liquid secondary markets, so that informed consumers can resell domestic currency assets without uninformed consumers noticing. It seems that (i) is sufficient if either type of consumers are the marginal buyers of long-term assets, while (ii) is sufficient only if uninformed consumers are the marginal buyers.
} 
Finally, the results presented in this paper have implications for the debate on whether crises are due to inconsistent domestic policies or the result of self-fulfilling, and perhaps arbitrary, changes in consumers' expectations. The unpredictability of attacks and large associated devaluations have often been interpreted as suggesting the latter. This paper shows that this interpretation may not be warranted.

\section{References}

Abreu, D., Brunnermeier, K., 2003. Bubbles and crashes. Econometrica 71, 173-204.

Angeletos, G., Hellwig, C., Pavan, A., 2007. Dynamic global games of regime change: Learning, multiplicity, and the timing of attacks. Econometrica 75, 711-56.

Broner, F., 2002. On the timing of balance of payment crises: Disaggregated information and interest rate policy. Mimeo, CREI.

Burnside, C., Eichenbaum, M., Rebelo, S., 2001. Prospective deficits and the Asian currency crisis. Journal of Political Economy 109, 1155-97.

Cavallari, L., Corsetti, G., 2000. Shadow rates and multiple equilibria in the theory of currency crises. Journal of International Economics 51, 275-86.

Chamley, C., 2003. Dynamic speculative attacks. American Economic Review 93, 603-21.

Chari, V., Kehoe, P., 2003. Hot money. Journal of Political Economy 111, 1262-92.

Chari, V., Kehoe, P., 2004. Financial crises and herds. Journal of Economic Theory 119, 19-33.

Drazen, A., Helpman, E., 1987. Stabilization with exchange rate management. Quarterly Journal of Economics 102, 835-56.

Edwards, S., 1997. The Mexican peso crisis: How much did we know? When did we know it? The World Economy 21, 1-30.

Flood, R., Garber, P., 1984a. Collapsing exchange-rate regimes: Some linear examples. Journal of International Economics 17, 1-13. 
Flood, R., Garber, P., 1984b. Gold monetization and gold discipline. Journal of Political Economy 92, 90-107.

Flood, R., Jeanne, O., 2005. An interest rate defense of a fixed exchange rate? Journal of International Economics 66, 471-84.

Frankel, J., Schmukler, S., 2000. Country funds and asymmetric information. International Journal of Finance and Economics 5, 177-95.

Garber, P., 1998. Derivatives in international capital flows. NBER Working Paper No. 6623.

Guimarães, B., 2006. Dynamics of currency crises with asset market frictions. Journal of International Economics 68, 141-158.

Halac, M., Schmukler, S., 2004. Distributional effects of crises: The financial channel. Economía 5, $1-67$.

Krugman, P., 1979. A model of balance-of-payments crises. Journal of Money, Credit, and Banking $11,311-25$.

Jeanne, O., 1999. Currency crises: A perspective on recent theoretical developments. CEPR Discussion Paper No. 2170.

Lahiri, A., Végh, C., 2003. Delaying the inevitable: Interest rate defense and balance of payments crises. Journal of Political Economy 111, 404-24.

Morris, S., Shin, H., 1998. Unique equilibrium in a model of self-fulfilling currency attacks. American Economic Review 88, 587-97.

Morris, S., Shin, H., 1999. A theory of the onset of currency attacks. In: Agenor, P., Miller, M., Vines, D., Weber, A. (Eds.), The Asian financial crisis: Causes, contagion and consequences. Cambridge University Press, Cambridge, pp. 230-55.

Obstfeld, M., 1986. Rational and self-fulfilling balance-of-payments crises. American Economic Review 76, 72-81.

Ó Gráda, C., White, E., 2003. The panics of 1854 and 1857: A view from the Emigrant Industrial Savings Bank. Journal of Economic History 63, 213-40. 
Pastine, I., 2002. Speculation and the decision to abandon a fixed exchange rate regime. Journal of International Economics 57, 197-229.

Rigobon, R., 2002. Disinflation and fiscal reform: A neoclassical perspective. Journal of International Economics 58, 265-97.

Rochon, C., 2006. Devaluation without common knowledge. Journal of International Economics 70, 470-89.

\section{Appendix A: Demand for real balances}

Let $a$ denote consumer's wealth in real terms. The consumer's flow budget constraint is given by

$$
\dot{a}_{t}=r \cdot a_{t}+y-c_{t}-\left(r+\frac{\dot{S}_{t}}{S_{t}}\right) \cdot \frac{M_{t}}{S_{t}}
$$

when $S$ is continuous at $t$, and by

$$
\Delta a_{t}=-\frac{\Delta S_{t}}{S_{t}^{+}} \cdot \frac{M_{t}^{+}}{S_{t}^{-}}
$$

where $S_{t}^{-} \equiv \lim _{\tau \rightarrow t^{-}} S_{\tau}, S_{t}^{+} \equiv \lim _{\tau \rightarrow t^{+}} S_{\tau}$, and $M_{t}^{+} \equiv \lim _{\tau \rightarrow t^{+}} M_{\tau}$, when $S$ is discontinuous at $t .^{28}$

Integrating and imposing the transversality condition I get the intertemporal budget constraint

$$
a_{t}+\frac{y}{r}=\int_{t}^{\infty}\left(c_{\tau}+\left(r+\frac{\dot{S}_{\tau}}{S_{\tau}}\right) \cdot \frac{M_{\tau}}{S_{\tau}}\right) \cdot e^{-r \cdot(\tau-t)} \cdot d \tau+\sum_{i} \frac{\Delta S_{\tau_{i}}}{S_{\tau_{i}}^{+}} \cdot \frac{M_{\tau_{i}}^{+}}{S_{\tau_{i}}^{-}} \cdot e^{-r \cdot\left(\tau_{i}-t\right)},
$$

where $\tau_{i}$ denotes the times at which $S$ is discontinuous.

The maximization problem is simplified substantially by the assumption that consumers are risk neutral with respect to $c_{t}$. As a result, the Lagrange multiplier is constant and equal to 1 .

The first order condition with respect to real money balances is then given by

$$
\phi^{\prime}\left(\frac{M_{t}}{S_{t}}\right)=\left(r+\pi_{t}^{e}\right)
$$

\footnotetext{
${ }^{28}$ To understand the expression, consider the following case. There is 1 consumer, who holds 2 pesos at $t^{-}$. The exchange rate equals $1 \mathrm{P} / \$$ and reserves equal 1 dollar at $t^{-}$. The consumer runs on the currency at $t$, being able to exchange 1 peso for dollars before reserves are exhausted and the currency is devalued to $S_{t^{+}}=2 \mathrm{P} / \$$. The consumer $\operatorname{loses} \frac{\Delta S_{t}}{S_{t}^{+}} \cdot \frac{M_{t}^{+}}{S_{t}^{-}}=\frac{1 \mathrm{P} / \$}{2 \mathrm{P} / \$} \cdot \frac{1 \mathrm{P}}{1 \mathrm{P} / \$}=0.50 \$$.
} 
where $\pi_{t}^{e}$ denotes the expected losses from devaluation. Note that the expected losses from devaluation $\pi_{t}^{e}$ are not equal to the expected rate of devaluation $-S_{t} \cdot E_{t}\left[d\left(S_{t}^{-1}\right)\right] / d t$. The reason is that the losses due to discrete devaluations are suffered only on the post-devaluation money holdings $M_{t}^{+}$.

\section{Appendix B: Proof of Proposition (2)}

I will prove the five properties of $T_{\alpha}(\bar{R})$ listed in the main text. That this properties imply the proposition is trivial.

(i) Let us assume that informed consumers attack at time $T_{K F G}(\bar{R})$, and that uninformed consumers hold an amount $L(0)$ of domestic currency until they observe an attack by informed consumers. At time $T_{K F G}(\bar{R})$, Condition (6) holds by definition. As a result, Conditions (ii) and (iii) in Proposition (1) are satisfied. In addition, given that in the KFG equilibrium the shadow exchange rate as a function of $\bar{R}, S_{\bar{R}}^{S}$, is always equal to 1 , the expected losses from devaluation $\pi_{t}^{e} \equiv 0$. As a result, Condition (i) in Proposition (1) is also satisfied. This shows that the KFG outcome is also an equilibrium of the private information game.

(ii) This is equivalent to Condition (ii) in Proposition (1).

(iii) Let us assume that there exists an equilibrium of the game when $\alpha \in\left[\alpha^{*}, 1\right]$ in which $T(\bar{R})>T_{K F G}(\bar{R})$. This implies that $\bar{R}>L^{S}-D_{T(\bar{R})}^{-}$which, together with Condition (iii) in Proposition (1), implies that $(1-\alpha) \cdot L_{t}^{U}>L^{S}$. Since informed consumers never attack when the attack would lead to a revaluation, the expected losses from devaluation $\pi_{t}^{e} \geq 0$. Since $L^{\prime}\left(\pi_{t}^{e}\right)<0$, it follows that $L_{t}^{U} \leq L(0)$. As a result, $(1-\alpha) \cdot L(0)>L^{S}$, which can be rewritten as $\alpha<\alpha^{*}$, a contradiction.

(iv) Let us first assume that there exists an equilibrium of the game when $\alpha \in\left(0, \alpha^{*}\right)$ in which $T(\bar{R})>T_{K F G}(\bar{R})+\mu^{-1} \cdot\left(\alpha^{*}-\alpha\right) \cdot L(0)$. Using the fact that $\mu \cdot\left(T(\bar{R})-T_{K F G}(\bar{R})\right)=D_{T(\bar{R})}-D_{T_{K F G}(\bar{R})}$, this implies that $D_{T(\bar{R})}-D_{T_{K F G}(\bar{R})}>\left(\alpha^{*}-\alpha\right) \cdot L(0)$. Using the fact that $D_{T_{K F G}(\bar{R})}=L^{S}-\bar{R}$ and the definition of $\alpha^{*}$, this implies that $D_{T(\bar{R})}+\bar{R}>(1-\alpha) \cdot L(0)$. Using the fact that $L_{t}^{U} \leq L(0)$, this implies that $D_{T(\bar{R})}+\bar{R}>(1-\alpha) \cdot L_{t}^{U}$. This contradicts Condition (iii) in Proposition (1). Let us next assume that there exists an equilibrium of the game when $\alpha \in\left(0, \alpha^{*}\right)$ in which $T(\bar{R})>$ $T_{K F G}(\bar{R})+\mu^{-1} \cdot \bar{R}$. It is easy to show that this condition is equivalent to $T(\bar{R})>T_{K F G}(0)$. For 
the equilibrium under consideration, let $T_{M A X}=\sup \{T: \exists \bar{R}$ such that $T(\bar{R})=T\}$ be the latest possible crisis time. As time tends to $T_{M A X}$, the crisis hazard rate tends to $\infty$. In addition, the conditional devaluation is bounded away from 0 since $T_{M A X} \geq T(\bar{R})>T_{K F G}(0)$. As a result, as time tends to $T_{M A X}$ the expected losses from devaluation tend to $+\infty$ and $L_{t}^{U}$ tends to 0 . This implies that there cannot be enough reserves left for informed consumers for crisis times in a neighborhood of $T_{M A X}$, which cannot happen in equilibrium.

(v) Starting from the KFG equilibrium of the game when $\alpha \in\left(0, \alpha^{*}\right)$, we can construct another equilibrium in which the attack takes place at time $T^{\prime}$ for any

$$
T^{\prime} \in\left[T_{K F G}(\bar{R}), T_{K F G}(\bar{R})+\mu^{-1} \cdot \min \left\{\left(\alpha^{*}-\alpha\right) \cdot L(0), \bar{R}\right\}\right]
$$

This new equilibrium is characterized by the same functions $T(\cdot)$ and $L_{t}^{U} \equiv L(0)$ as the KFG equilibrium, except that for the particular $\bar{R}$ in consideration, the attack takes place at $T^{\prime}$ instead of at time $T_{K F G}(\bar{R})$. Since the distribution $g(\cdot)$ has no atoms, this change does not affect $\pi_{t}^{e}$ and, thus, the same $L_{t}^{U}$ satisfies Condition (i) in Proposition (1). ${ }^{29}$ Since $T^{\prime}>T_{K F G}(\bar{R})$, Condition (ii) in Proposition (1) is satisfied. Lastly, using an argument analogous to that used to prove (iv) above, it is easy to show that Condition (iii) in Proposition (1) is also satisfied.

\section{Appendix C: Proof of Lemma (4)}

The proof has a number of intermediate steps:

(i) $\bar{R}(t)$ is either empty or has a single element for every $t$. From Conditions (ii) and (iii) in Proposition (1), and Condition (iv) in Lemma (3), it follows that $\bar{R}(t)$ can have at most two elements: $\bar{R}_{1}=(1-\alpha) \cdot L_{t}^{U}-D_{t}$, and $\bar{R}_{2}=L^{S}-D_{t}$. Condition (ii) in Proposition (1) implies that $\bar{R}_{1} \geq \bar{R}_{2}$ and Condition (iv) in Lemma (3) implies that $\bar{R}_{1} \leq \bar{R}_{2}$. This is possible only if $\bar{R}_{1}=\bar{R}_{2}$, so $\bar{R}(t)$ has at most one element.

Let

$$
\Omega=\{t: \bar{R}(t) \neq \emptyset\} .
$$

\footnotetext{
${ }^{29}$ As noted in the proof of (iv), these strategies would not be an equilibrium if $T^{\prime}>T_{K F G}(\bar{R})+\mu^{-1} \cdot \bar{R}$. The reason is that if $T^{\prime}>T_{K F G}(0)$, the distribution of crisis times conditional on not having observed an attack before or at $T_{K F G}(0)$ would become degenerate at $T^{\prime}$, which cannot happen in equilibrium.
} 
(ii) $\Omega$ is dense in $\Omega^{\prime} \equiv[\inf \{\Omega\}, \sup \{\Omega\}]$. Assume $\exists \tau_{1}, \tau_{2} \in \Omega^{\prime}$ such that $\left[\tau_{1}, \tau_{2}\right] \cap \Omega=\emptyset$. Let $\tau_{1}^{\prime}=\max \left\{t \in \Omega: t<\tau_{1}\right\}$. Now we use Refinement (3). Condition (iv) in Lemma (3) implies that the large consumer can postpone the abandonment of the peg regardless of how small he is. As a result, he would refrain from attacking the currency at $\tau_{1}^{\prime}$ and enjoy a higher level of domestic currency holdings for a positive amount of time after $\tau_{1}^{\prime}$ before uninformed consumers react and before $\tau_{2}$. This contradicts $\tau_{1}^{\prime} \in \Omega$.

(iii) $\Omega=\Omega^{\prime} . T(\bar{R})$ is decreasing and, from (ii), its image is dense in $\Omega^{\prime}$. Assume $\tau \in \Omega^{\prime}$ but $\tau \notin \Omega$. Since $\Omega$ is dense, $\exists\left\{\tau_{1}, \ldots, \tau_{n}, \ldots\right\}$ such that $\tau_{n} \rightarrow \tau, \tau_{1}<\cdots<\tau_{n}<\tau_{n+1} \cdots<\tau$, and $\forall n$ $\tau_{n} \in \Omega$. (For $\tau=\inf \{\Omega\}$ a symmetric argument applies.) Let, for all $n, \alpha_{n} \equiv \bar{R}\left(\tau_{n}\right)$ (defined as the inverse of $T(\cdot)$ on $\Omega$ ). Then $\left\{\alpha_{1}, \ldots, \alpha_{n}, \ldots\right\}$ is a bounded decreasing sequence. Let $\alpha$ be its limit. If $T(\alpha)<\tau$, then $\tau_{n}$ is bounded away from $\tau$ and $\tau_{n} \not \nrightarrow \tau$. If $T(\alpha)>\tau$, then it is impossible that $\tau_{n}<\tau \forall n$. This implies $\Omega=\Omega^{\prime}$, and we denote $\Omega=\left[t_{0}, t_{1}\right]$

(iv) $T:\left[0, R_{M}\right] \rightarrow\left[t_{0}, t_{1}\right]$ is a continuous strictly decreasing function. This follows from the fact that $T(\bar{R})$ is one-to-one and decreasing.

(v) $T(0)=t_{1}$ satisfies $S_{T(0)}^{S}=1$. If $S_{T(0)}^{S}>1$, as $t \rightarrow T(0)$ the expected devaluation losses would tend to infinite since the hazard rate of crisis tends to infinite while the size of devaluation does not tend to zero. As a result, $L_{t}^{U} \rightarrow 0$, contradicting Condition (iii) of Proposition (1). $S_{T(0)}^{S}<1$ is not possible either since it contradicts Condition (ii) of Proposition (1). 

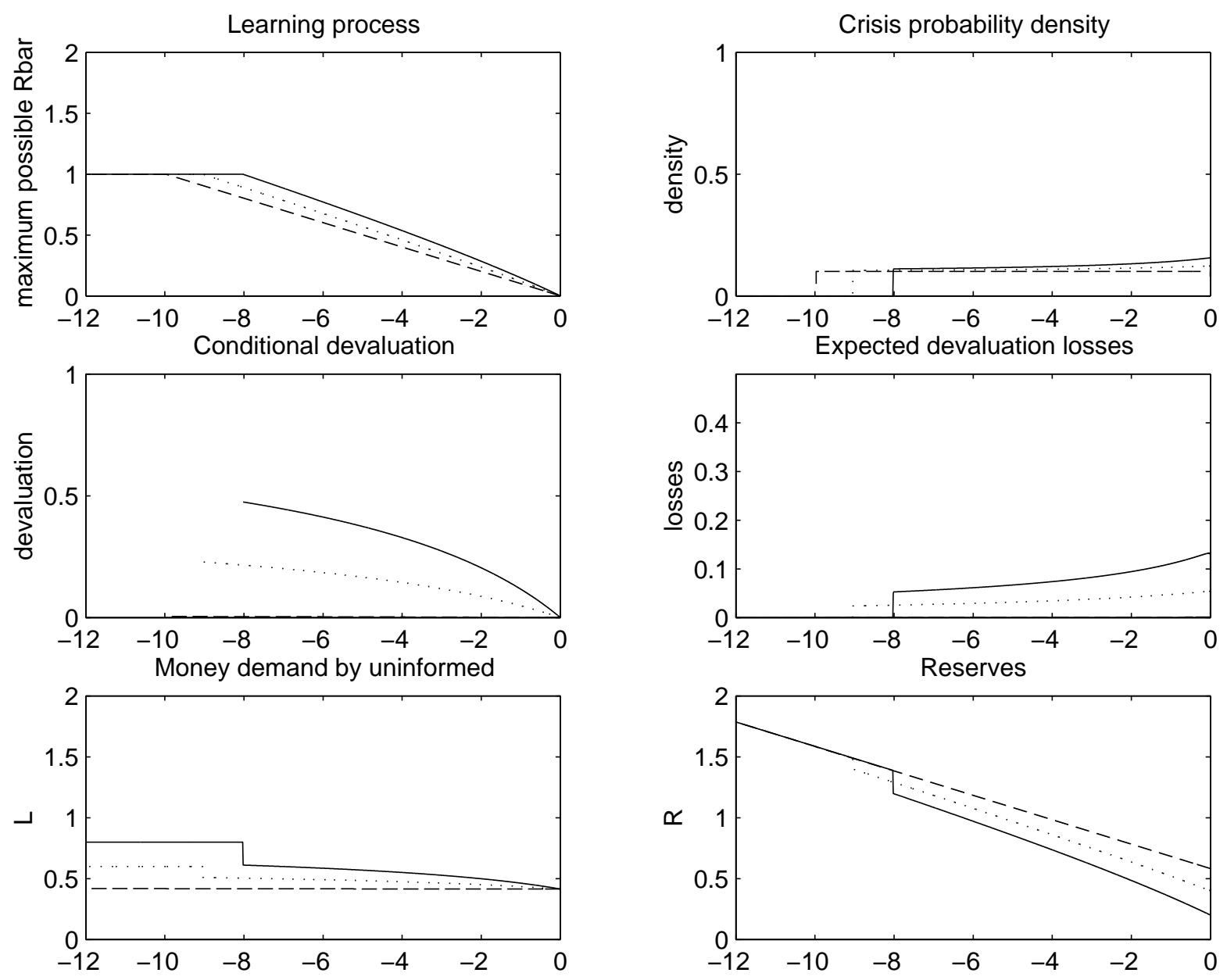

Figure 2: Equilibrium that survives the refinements. $\bar{R}$ is uniformly distributed on $[0,1]$. Dashed line: $\alpha \approx \alpha^{*}$. Dotted line: intermediate $\alpha$. Solid line: low $\alpha$. 